\title{
Dysostosis with brachydactyly
}

INSERM

\section{Source}

INSERM. (1999). Orphanet: an online rare disease and orphan drug data base. Dysostosis with brachydactyly. ORPHA:69028

Brachydactyly ('short digits') is a general term that refers to disproportionately short fingers and toes, and forms part of the group of limb malformations characterized by bone dysostosis. 